\title{
Alcohol Consumption Patterns: A Gender Comparative Study Among High School Youth in South Africa
}

\author{
Prudence Mafa ${ }^{1}$, Jabulani Calvin Makhubele ${ }^{1}$, Janetta Agnes Ananias ${ }^{2}$, Beatrice Namoonga Chilwalo ${ }^{2}$, Frans \\ Koketso Matlakala ${ }^{1}$, Selelo Frank Rapholo ${ }^{1}$, Anesu Svinurai ${ }^{1}$, Miriam Winnie Hasheela ${ }^{2}$, \\ Ndanyakuwa Ilonga Hamuse Tiberia ${ }^{2} \&$ Rachel Johanna Freeman ${ }^{2}$ \\ ${ }^{1}$ University of Limpopo, Private Bag X1108, Sovenga, South Africa \\ ${ }^{2}$ University of Namibia, Private Bag 13301, Windhoek, Namibia \\ Correspondence: Prof JC Makhubele, University of Limpopo, Private Bag X1108, Sovenga 0727, South Africa.
}

Received: November 21, 2018 Accepted: January 10, 2019 Online Published: January 16, 2019

doi:10.5539/gjhs.v11n2p92 URL: https://doi.org/10.5539/gjhs.v11n2p92

\begin{abstract}
Aim: The aim of this study was to examine the alcohol drinking patterns among young male and female alcohol drinkers.

Method: Data were collected though a questionnaire from 71 grade 11 learners who expressed that they had had an alcoholic drink in the preceding month. $62 \%$ of the respondents were male and the remaining $38 \%$ was represented by female learners. The data collected was analysed using the Statistical Package for the Social Science (SPSS).

Results: This study showed that young people begin using alcohol at a relatively young age. Furthermore, male drinkers have an earlier alcohol debut than their female counterparts. Beer, cider and wine were the most consumed beverages, with males more inclined to drink beer and females gravitating towards drinking wine. There was an even split between ciders in the study, with the majority of both male and female respondents indicating that their drink of choice was cider. Weekends are the most opportune moments for the youth to consume alcohol. Holidays are also earmarked by the youth to engage in alcohol consumption.

Conclusion: The results show that the age of alcohol debut is as low as 8 years for males and 10 years for females. Males have a higher prevalence of alcohol use than females. There is however no difference in binge drinking between the two gender as binge drinking and drinking to get drunk are the preferred methods of alcohol consumption for both genders.
\end{abstract}

Keywords: youth, alcohol consumption patterns, gender, binge drinking

\section{Introduction}

The act of alcohol drinking by young people has steadily increased over the years. While males are reported to be most likely to drink alcohol more than females (Onya \& Flisher, 2008; Owo, 2013), research has shown that the gender gap in alcohol consumption behaviour, particularly binge drinking, is narrowing (Ramsoomar \& Morojele, 2012). According to Schulte, Ramo, and Brown, (2009) the reduction of the gap between the two gender variables in terms of alcohol use can be attributed to an increase in opportunities for women which allow them to perform roles traditionally set aside for men, enabling and encouraging them to drink more.

During the pre-colonial era, alcohol was consumed mainly during special occasions and was usually preserved for elders and prominent members of society including traditional leaders. Alcohol consumption was thus rare among youth and women of childbearing age (Peltzer \& Ramlagan, 2007). Studying the effects of gender on alcohol use assist societies in properly addressing alcohol abuse by dispelling false assumptions about male or female drinking behaviour. Schulte, Ramo, and Brown (2009) warn against assuming that women do not drink heavily as this assumption may lead to women's drinking problems being overlooked or underestimated, while associating heavy drinking with masculinity may lead to minimization of problem drinking by male drinkers.

It has been reported that women do not react to alcohol as men do. Gunasekara and Wilson, (2010) indicate that women start to experience alcohol-related problem at a higher rate than men as women have less water in their bodies as compared to men, thus making women get drunk more quickly than men do. This also increases women's risk to alcohol harm. 


\subsection{Gender Difference in Alcohol Consumption}

South Africa has been identified as a hard drinking country. It is estimated that South Africans consume about 5 billion litres of alcohol annually. This quantity translates to 9 to 10 litres of pure alcohol per person and puts the country amongst the higher alcohol consuming nations in the world (World Health Organization, 2017). About $40.6 \%$ of the population are current drinkers, with about $25 \%$ of the current drinkers engaging in heavy episodic drinking. Reports indicate that on average, a male drinker consumes 32.8 litres of pure alcohol per year, while a female drinker consumes 16 litres of pure alcohol per year. This pattern of alcohol consumption is over half more than the world average for men and $80 \%$ more that the world average for women (World Health Organization, 2015).

These differences can be attributed to the possibility of respondents under-reporting their alcohol use, particularly females (Peltzer, Davids, \& Njuho, 2011) as alcohol use is often stigmatized (Dumbili, 2013).

\subsection{Effects of Alcohol on Male and Female Drinkers}

The use and abuse of alcohol has dire consequences for users and nonusers alike, with most of these consequences occurring while one is intoxicated. It is worth noting that some of the consequences are also different for both men and women. Women are more likely to experience direct or indirect effects of alcohol use and abuse than men. One of the factors that contribute to sexual violence is alcohol use, either by the victim or the perpetrator. Though sexual violence can happen to anyone, a review of literature by Dawgert, (2009) shows that a high percentage of victims (both male and female) of sexual abuse report to have been intoxicated at the time of the assault. The perpetrator is likely to have been using alcohol when they committed the crime. Some victims of sexual and/or domestic violence use substances such as alcohol to cope. About $25 \%-75 \%$ of sexual abuse survivors report to have drinking problems (Dawgert, 2009).

Long term gender specific impacts of alcohol use include an increased risk of breast cancer, reduced fertility, unplanned pregnancy, sexually transmitted diseases, heavy, irregular or cessation of periods in women. Drinking alcohol during pregnancy increases the risk of miscarriage, stillbirth, low birth weight, premature birth (Gunasekara \& Wilson, 2010) and Foetal Alcohol Syndrome (Viljoen, Graig, Hymbaugh, Boyle, \& Blount, 2003). Immediate effects of alcohol use on school-going youth for both gender as reported in Chauke, van der Heever, and Hoque, (2015) include school absenteeism by both gender. More male students $(6.7 \%)$ reported to be absent from school, failed to do homework $(11.0 \%)$, and were unable to study for a test after drinking alcohol compared to their female counterparts $(3.3 \%, 7.6 \%$, and $6.3 \%$ respectively).

\subsection{Youth Drinking Trends}

Studies by Greydanus and Patel, (2005); Morojele, Parry, Brook, and Kekwaletswe, (2009) and Owo (2013) indicate that alcohol is the substance most commonly used by high school learners, with about $51.4 \%-76 \%$ of the respondents reporting that they have used alcohol in their lifetime. Carter, Filoche, and McKenzie, (2017) established that it is common practice for young people to engage in risky drinking, with males drinking more frequently and consuming more alcohol per session than female drinkers.

\subsection{Age of First Use}

In addition to the difference in the consumption rate, there is also a difference in the age of debut of substance use between males and females. Males tend to start using substances at an earlier age in comparison to their female counterparts. Tshitangano and Tosin, (2016) found that $67 \%$, of the male learners started using substances between the ages of 13 and 15 years, whereas the female respondents mostly began substance use between the ages of 16 and 18 years. Additionally, a review of literature by Ramsoomar and Morojele, (2012) shows that $12 \%$ of South African youth began using alcohol before the age of 13 years.

\subsection{Drink of Choice/What Youth Drink}

Youth trend of alcohol drinking follow those exhibited by older drinkers in the country and internationally. Van Walbeek and Blecher, (2014) indicate that beer is the most preferred alcoholic beverage by males. Men also prefer to drink spirits. Females have a greater preference for wine and flavoured alcohol beverages such as cider and spirit coolers. Flavoured beverages are also a favourite among young drinkers. These results are in line with what World Health Organization, (2004) reported. Commercially brewed beverages are not the only alcoholic drinks consumed by the youth. Onya and Flisher (2008) as well as Gugu and Davison, (2017) report consumption of traditionally brewed alcohol by young drinkers.

\subsection{Quantity and Frequency/How Youth Drink}

There is evidence to suggest that there is high prevalence of hazardous drinking patterns (binge drinking and being 
frequently intoxicated) amongst youth. Binge drinking, which is the consumption of five or more drinks per drinking session is one of the most common patterns of alcohol consumption among young people (Ashley, Levine, $\&$ Needle, 2006). This pattern of drinking is a major contributor to the global burden of disease and has been listed as the third leading factor for premature deaths and disabilities in the world (World Health Organization, 2015) and is said to be more common among males (Parry, 1998; Seggie, 2012). A binge drinking prevalence rate of 9.6\% and $9.0 \%$ in male and female youths respectively was recorded by (Ghuman, Meyer-Weitz, \& Knight, 2012). Binge drinking was reported to be on the increase by Ramsoomar and Morojele, (2012) with 27.3\% reported in 1998 to $36.6 \%$ in 2003 .

It has been found that although young people may be indulging in excessive alcohol consumption, the frequency of such consumption differed. Data from Parry (1998), as well as Smuts, (2009) showed that alcohol consumption occurs mainly on weekend evenings and increases over holiday periods such as Christmas and Easter holidays. It can be deduced from the results of studies that a significant number of youth use alcohol frequently. About $32 \%$ of the youth report to have engaged in binge drinking during the preceding month, while $21 \%$ of current alcohol consumers reported binge drinking twice or more in the preceding month. A small percentage $(1.1 \%)$ of respondents reported to consume alcohol daily (Ghuman et al., 2012). About $31 \%$ use alcohol more than 20 days a month and $10 \%$ six to nineteen days a month, with $29.5 \%$ reporting they consume alcohol at least once a week (Simbee, 2012).

The aim of this study was to examine the alcohol drinking patterns among young male and female alcohol drinkers.

\section{Methods}

A quantitative descriptive study was carried out with a total of 71 youth (62\% males and $38 \%$ females) from Musina Town, Limpopo Province, South Africa. Their age ranged from 15 and 22 years. The participants were sampled from Musina High School. The school is situated in a border town where South Africa borders with Zimbabwe. The school provides for Black/African learners of both sexes from grade 8-12. All respondents were grade 11 learners who indicated that they had had an alcoholic drink in the preceding month.

Data were collected from 71 participants who are current alcohol drinkers, using a self-administered questionnaire which included demographic factors, age of first alcohol use, preferred alcoholic drink, time of day when alcohol is consumed, amount of alcohol consumed in one session, frequency of alcohol consumption, number of times of being drunk. As English is the medium of instruction at the school, the questionnaire was also written in English.

The data collected were cleaned, coded, captured then analysed using the Statistical Package for the Social Science (SPSS) system to analyse quantitative data. SPSS is a comprehensive system for analysing data which can take data from almost any type of file and use them to generate tabulated reports, charts, and plots of distributions and trends, descriptive statistics, and complex statistical analysis (Gilman \& Weber, 2007).

\section{Results}

\subsection{Distribution of Male and Female Drinkers}

71 respondents reported to be alcohol drinkers, with 44 of them being male and 27 females. The male drinkers represented $62 \%$ of the 71 respondents, while the female drinkers represented $38 \%$ of the learners who reported to be current drinkers.

Table 1. Age of alcohol debut

\begin{tabular}{lllllll}
\hline Age & Male respondents & $\mathbf{\%}$ & Female respondents & $\mathbf{\%}$ & Total & $\mathbf{\%}$ \\
\hline $\mathbf{1 0}$ years old or less & 1 & 2.3 & - & - & 1 & 1.4 \\
$\mathbf{1 1}-\mathbf{1 2}$ years old & 3 & 6.8 & - & - & 3 & 4.2 \\
$\mathbf{1 3}-\mathbf{1 4}$ years old & 6 & 13.6 & 1 & 3.7 & 7 & 9.9 \\
$\mathbf{1 5}-\mathbf{1 6}$ years old & 9 & 20.5 & 7 & 25.9 & 16 & 22.5 \\
$\mathbf{1 7}$ years or older & 18 & 40.9 & 14 & 51.9 & 32 & 45.0 \\
Can't remember & 7 & 15.9 & 5 & 18.5 & 12 & 17.0 \\
Total & 44 & 100 & 27 & 100 & 71 & 100 \\
\hline
\end{tabular}

Table 1 shows that of the 44 male respondents, only $2.3 \%(n=1)$ began drinking alcohol when they were younger 
than 10 years old. $6.8 \%(\mathrm{n}=3)$ learners indicated that their alcohol debut was between the ages of 11 and 12 years old. $13.6 \%(n=6)$ started using alcohol when they were between the ages of 13 and 14. 15-16 years was the age of initiation for $20.5 \%(n=9)$ of the respondents. Most $40.9 \%(n=18)$ had their alcohol debut at the age of 17 years or older, with $15.9 \%(\mathrm{n}=7)$ not remembering when they had their first alcoholic beverage.

27 female respondents reported to be alcohol users. 3.7\% $(\mathrm{n}=1)$ started consuming alcohol between the ages of 13 and 14 years. $25.9 \%(\mathrm{n}=7)$ began using alcohol when they were between the ages of 15 and 16 . The majority $51.9 \%$ $(n=14)$ of the female respondents had their alcohol debut when they were 17 years or older, with $18.5 \%(n=5)$ stating that they could not remember the age at which they had their first alcoholic drink.

The data regarding age of initiation shows that of all the 71 drinkers, $1.4 \%(\mathrm{n}=1)$ had their first alcoholic drink when they were 10 years or younger. $4.2 \%(n=3)$ had their first alcoholic beverage when they were between the ages of 11 and 12 years. 9.9\% $(\mathrm{n}=7)$ of the respondents were between the ages of 13 and 14 when they first consumed alcohol. 22.5\% $(\mathrm{n}=16)$ had their alcohol debut when they were between the ages of 15 and 16. Most $45 \%(n=32)$ of the learners were 17 years or older, with $17 \%(n=12)$ indicating that they could not remember the age at which they first consumed alcohol.

\subsection{Preferred Type of Alcohol}

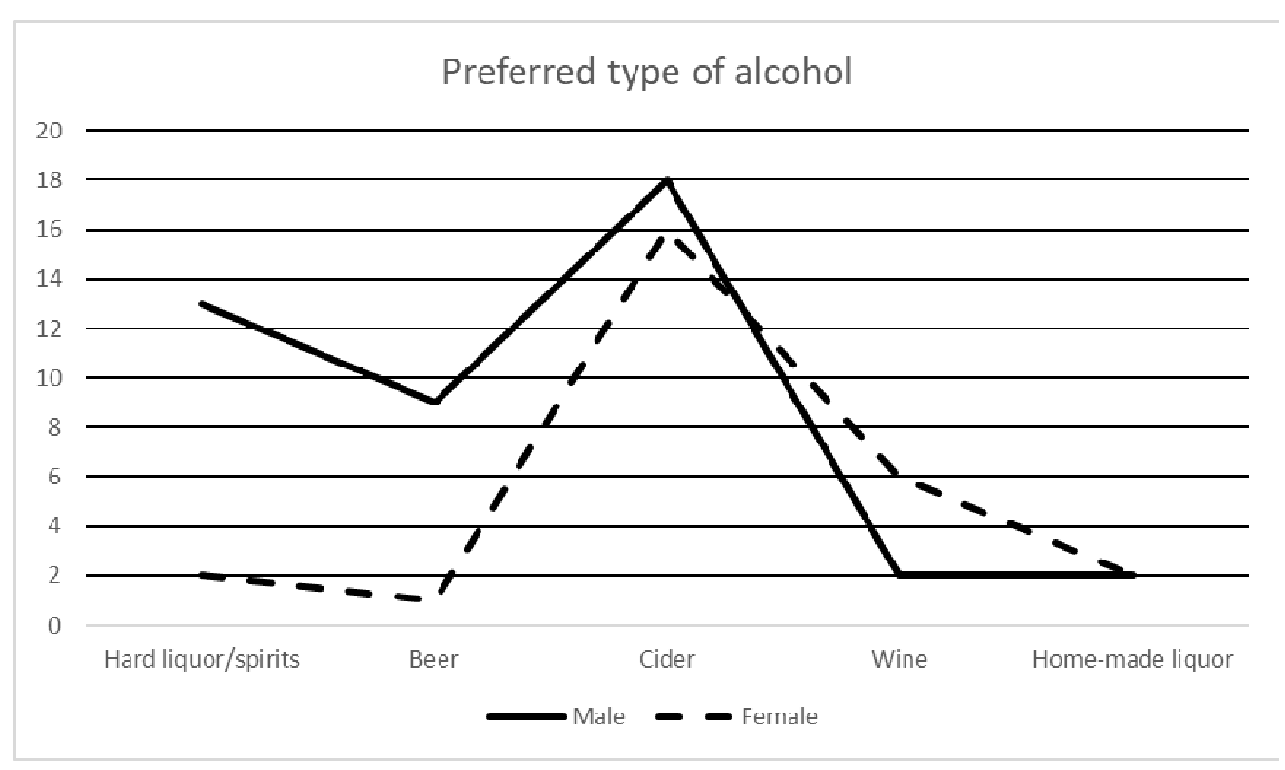

Figure 1. Type of alcohol preferred by the youth

Figure 1 shows that $29.6 \%(n=13)$ of the male respondents preferred to drink hard liquor/spirits. Beer was a drink of choice for $20.5 \%(n=9)$ of the male learners. Cider was a favourite for $40.9 \%(n=18)$ of the male alcohol consumers. $4.5 \%(\mathrm{n}=2)$ indicated that wine was their drink of choice, with the same number $(4.5 \%)$ of male learners indicating that their preferred drink was home-made liquor.

$7.4 \%(n=2)$ of the female alcohol users preferred to drink hard liquor/spirits. Beer was a drink of choice for 3.7\% $(n=1)$. Cider was a preferred drink for $59.3 \%(n=16)$ of the female learners. $22.2 \%(n=6)$ indicated that wine was their drink of choice, with $7.4 \%(\mathrm{n}=2)$ indicating that they preferred to drink home-made liquor.

The data presented show that $21.1 \%(\mathrm{n}=15)$ of the 71 alcohol users, prefer to drink hard liquor $/$ spirits. $14.4 \%$ $(\mathrm{n}=10)$ indicated that beer was their drink of choice. Cider is the most preferred with $47.9 \%(\mathrm{n}=34)$ stating that this drink was their favourite. $11.3 \%(n=8)$ learners' drink of choice was wine, with $5.6 \%(n=4)$ preferring to consume home-made liquor. 


\subsection{Time of Day When Youth Mostly Drink Alcohol}

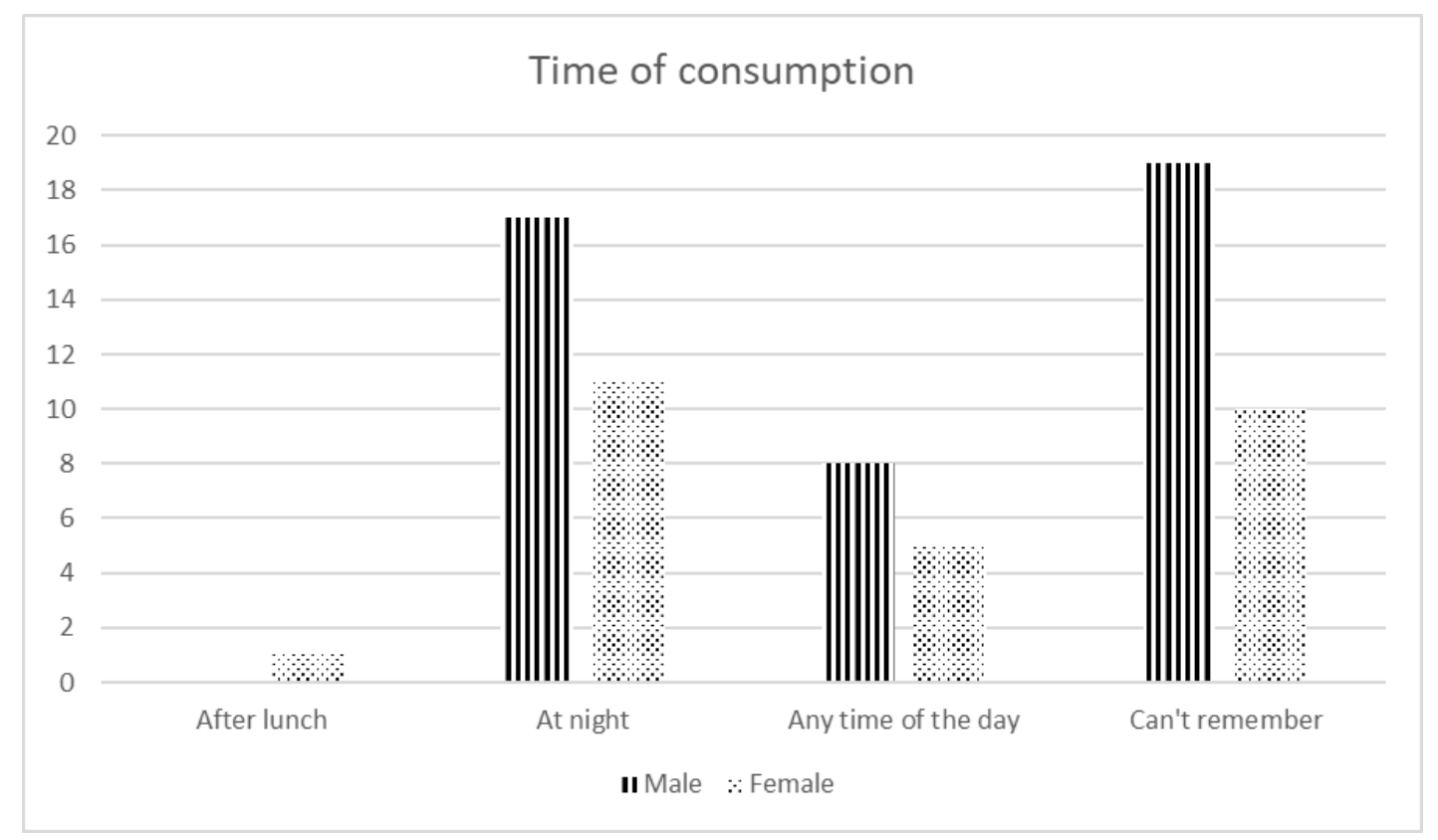

Figure 2. Time of day when youth mostly drink alcohol

$38.6 \%(n=17)$ of the male alcohol users drink at night. $18.2 \%(n=8)$ have their drinking sessions at any time of the day, with $43.2 \%(n=19)$ indicating that they could not remember the time of day that they mostly have their drinking sessions.

It was reported by $1.4 \%(n=1)$ of the female learners that they mostly drink during the day after lunch. The majority, $41 \%(n=11)$ reported that they mostly have their drinking sessions at night. $18 \%(n=5)$ consume alcohol at any time of the day, with $37 \%(n=10)$ not recalling what time of day they have their drinking sessions.

$1.4 \%(n=1)$ of the 71 alcohol users drink during the day. The majority, $39.4 \%(n=28)$ of the learners have their drinking sessions at night. $18.3 \%(\mathrm{n}=13)$ drink at any time of the day, with $40.9 \%(\mathrm{n}=29)$ indicating that they could not remember the time of day that they had their drinking sessions.

3.4 Amount of Alcohol Consumed in One Drinking Session

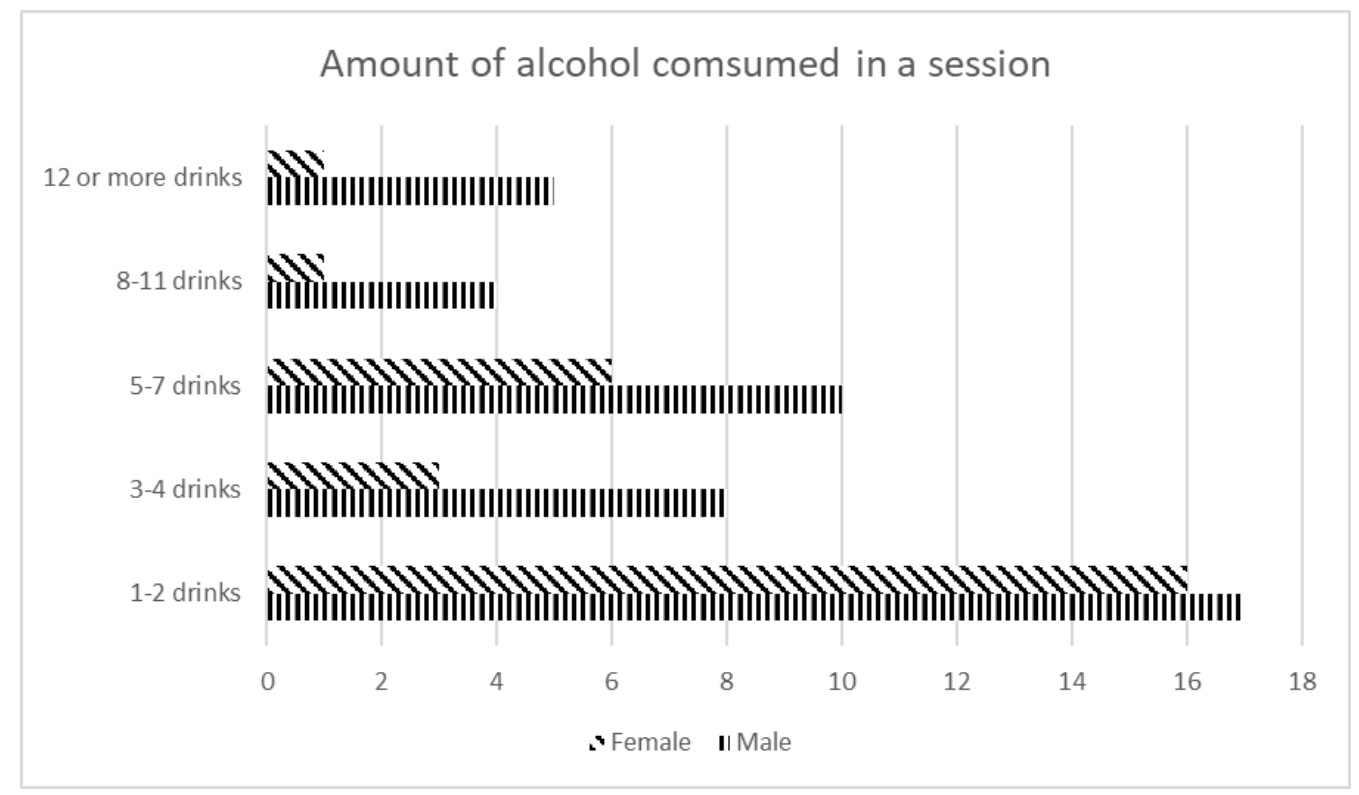

Figure 3. Amount of alcohol consumed in one drinking session 
Of the 44 male alcohol users, $38.6 \%(n=17)$ consume $1-2$ drinks in a session. $18.2 \%(n=8)$ consume $3-4$ drinks per session. $22.7 \%(n=10)$ reported consumption of 5-7 drinks in one sitting. A consumption of $8-11$ drinks in one session was reported by $9.1 \%(n=4)$, with $11.4 \%(n=5)$ consuming 12 or more drinks in one occasion.

The majority, $59.3 \%(n=16)$ of the 27 female alcohol users, consume $1-2$ drinks per session. $11.1 \%(n=3)$ have $3-4$ drinks in a session. A consumption of 5-7 drinks in one session was reported by $22.2 \%(\mathrm{n}=6)$ of the female learners $3.7 \%(n=1)$ consume $8-11$ drinks per session, with the same number $(3.7 \%)$ of the respondents reporting a consumption of 12 or more drinks in one session.

$46.3 \%(n=33)$ of the total alcohol users consume $1-2$ drinks in a drinking session. $15.5 \%(n=11)$ consume between 3 and 4 drinks in one sitting. $22.5 \%(n=16)$ have between 5 and 7 drinks per session. A consumption of $8-11$ drinks a session was reported by $7 \%(\mathrm{n}=5)$, with $8.5 \%(\mathrm{n}=6)$ indicating that they consume 12 drinks or more in a session.

\subsection{Frequency of Alcohol Consumption}

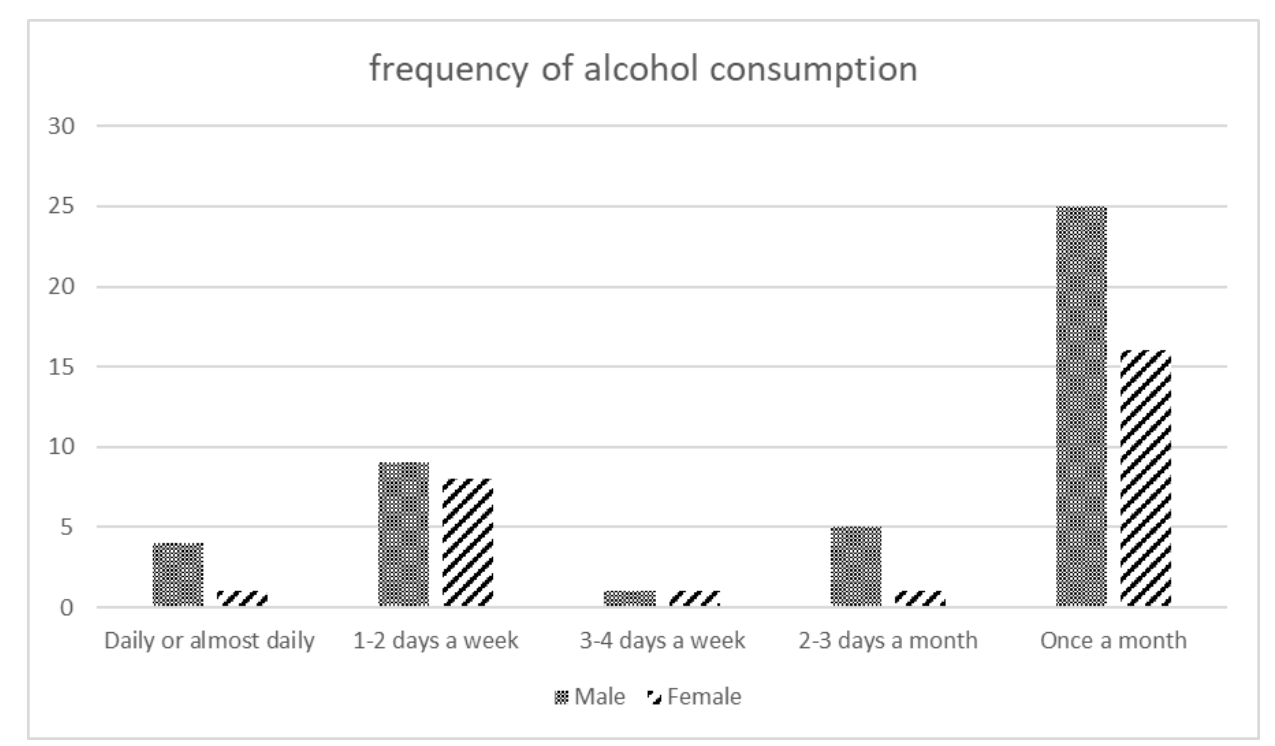

Figure 4. Frequency of alcohol consumption

The pattern of alcohol use was also assessed by the frequency at which youth consume alcohol. $9 \%(n=4)$ of the male alcohol users drank alcohol on a daily or almost daily basis. 2.3\% $(n=1)$ consume liquor 3-4 days a week. $20.5 \%(n=9)$ drink alcohol $1-2$ days a week. $11.4 \%(n=5)$ reported to drink 2-3 days a month, with the majority $56.8 \%(\mathrm{n}=25)$ consuming alcohol once in a month.

$3.7 \%(n=1)$ of the female drinkers consumed alcohol almost on a daily basis. The same number (3.7\%), reported to be consuming alcohol 2-4 days a week. $29.6 \%(n=8)$ of the female alcohol users drink alcohol $1-2$ days a week. One person (3.7\%) indicated that they consume alcohol 2-3 days a month, with the majority $59.3 \%(n=16)$ of the users consuming alcohol once a month.

$7 \%(n=5)$ of all the alcohol users drink almost daily. $2.8 \%(n=2)$ consume alcohol $3-4$ days a week. $23.9 \%(n=17)$ drink alcohol 1-2 days a week. It was reported by $8.5 \%(n=6)$ of the users that they drink $2-3$ days a month, with the majority $57.8 \%(n=41)$ consuming alcohol once a month. 


\subsection{Number of Times of Being Drunk}

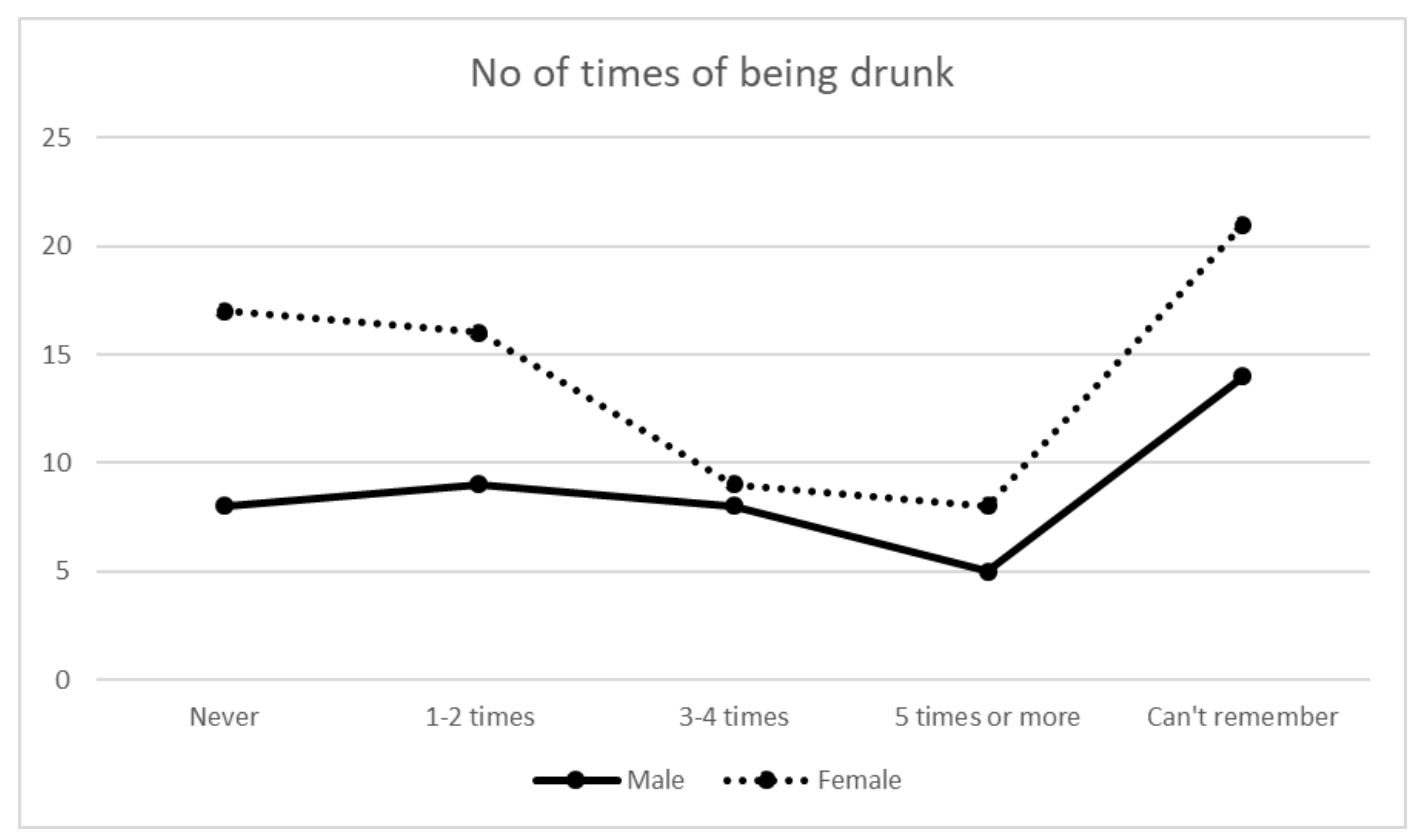

Figure 5. Number of times of being drunk

To have a clear picture of the pattern of alcohol use, the respondents were asked about the number of times they have ever been drunk. $18.2 \%(\mathrm{n}=8)$ of the male alcohol users reported to have never been drunk. $20.5 \%(\mathrm{n}=9)$ have been drunk 1 or 2 times. $18.2 \%(n=8)$ reported to have been drunk on $3-4$ occasions. $11.3 \%(n=5)$ have been drunk on 5 or more occasions, with the majority $31.8 \%(n=14)$ not remembering the number of occasions on which they have been drunk.

$33.3 \%(n=9)$ of the female users have never been drunk. $22.5 \%(n=16)$ have been drunk on 1 or 2 occasions. One respondent (3.7\%) has been drunk 3-4 times. $11.1 \%(\mathrm{n}=3)$ of the female learners have been drunk on 5 or more occasions, with the majority $26 \%(\mathrm{n}=7)$ indicating that they could not recall the number of times they have been drunk.

Of the 71 alcohol users, $23.9 \%(n=17)$ had never consumed alcohol until they were in a drunk state. $22.5 \%(n=16)$ have been drunk 1 or 2 times. $12.7 \%(\mathrm{n}=9)$ of the users reported to have been drunk on $3-4$ occasions. $11.3 \%(\mathrm{n}=8)$ have been drunk 5 or more times, with the majority, $29.6 \%(\mathrm{n}=21)$ indicating that they could not remember the number of times they have been drunk.

\section{Discussion}

This study showed that young people begin using alcohol at a relatively young age. Results from the study indicate that youth begin using alcohol while under the age of 16 years. Furthermore, male drinkers have an earlier alcohol debut than their female counterparts. These findings confirm what Tshitangano and Tosin, (2016) have found in their study where, $67 \%$, of the male learners started using substances between the ages of 13 to 15 years. A study done by Madu and Matla, (2003) in the Limpopo Province also established that young people's onset of substance use is usually under the age of 16 years.

Of the current drinkers in this study, $62 \%$ were males and $38 \%$ were female. These results resonate with studies by (Flisher, Parry, Evans, Muller, \& Lombard, 2003; Leteka, 2007; Chauke, van der Heever, \& Hoque, 2015) which showed that males are more prone to drinking alcohol than females.

Beer, cider and wine were the most consumed beverages, with males more inclined to drink beer and females gravitating towards drinking wine. There was an even split between ciders in the survey, with the majority of both male and female respondents indicating that their drink of choice was cider. Earlier research by Newman, Shell, Ming, Jianping, and Maas, (2006) and later research by Chauke et al., (2015), both show that wine is a drink of choice for women whereas men prefer to drink beer. The current study has however also revealed that there is a small percentage $(5.6 \%)$ of young people who drink traditional beer and some who drink all sorts of alcohol they 
can have access to. In Gugu and Davison, (2017) it was easier for participants to access traditionally brewed alcohol as it as available next to their places of residences and was cheaper than commercially brewed alcohol. The study has shown that male and female drinkers engage similar patterns of binge drinking.

Weekends are the most opportune moments for the youth to consume alcohol. Holidays are also earmarked by the youth to engage in alcohol consumption. The respondents in Smuts, (2009) reported an increased consumption of alcohol during holidays compared to their regular drinking over the weekend. The frequency of the drinking reported in the current study was daily; almost daily; once a month; twice a month; and every weekend for both male and female drinkers. It was found by other researchers (Greydanus \& Patel, 2005) that a small percentage drink on a daily basis, while Simbee, (2012) also found out some youth drink once a week. Madu and Matla, (2003) as well as (WHO/UNDCP Global Initiative on Primary Prevention of Substance Abuse., World Health Organization., \& United Nations International Drug Control Programme., 2003) also support these findings that young people mostly drink on weekends.

\section{Conclusion}

The results of the current study have shown that female drinkers engage in risky alcohol drinking patterns as much as males do. This could mean that South Africa may continue to have a high number of Foetal Alcohol Syndrome. Although the study indicated that female drinking patterns are resembling those of male, there still exist a difference in the prevalence of use amongst the two gender, with a bigger percentage of males consuming alcohol than females. Given that female drinkers engage in risky alcohol drinking, they too need assistance in seeking treatment which should be designed in a way that addresses their needs such as childcare. Stereotypes about male and female drinking patterns should be dispelled so that problem drinking can be properly addressed. Like in previous studies on self-reporting alcohol use pattern such as (Peltzer et al., 2011), respondents may have underreported their drinking behaviour.

\section{Funding}

This study was wholly funded by National Research Foundation of South Africa.

\section{Competing Interests Statement}

The authors declare that there are no competing or potential conflicts of interest regarding the publication of the paper.

\section{References}

Ashley, J., Levine, B., \& Needle, R. H. (2006). Substance Abuse and HIV/AIDS in Sub-Saharan Africa. The African Journal of Drug \& Alcohol Studies, 5(2).

Carter, K., Filoche, S., \& McKenzie, S. (2017). Alcohol and young people: A review of New Zealand and other international literature. Report commissioned by the Health Promotion Agency. Wellington: Health Promotion Agency.

Chauke, T. M., van der Heever, H., \& Hoque, M. E. (2015). Alcohol use amongst learners in rural high school in South Africa. African Journal of Primary Health Care \& Family Medicine, 7(1). https://doi.org/10.4102/phcfm.v7i1.755

Dumbili, E. (2013). Changing Patterns of Alcohol Consumption in Nigeria: An Exploration of Responsible factors and Consequences. Medical Sociology, 7(1).

Flisher, A. J., Parry, C. D. H., Evans, J., Muller, M., \& Lombard, C. (2003). Substance Use by Adolescents in Cape Town: Prevalence and correlates. $J$ Adolesc Health, 32, 58-65. https://doi.org/10.1016/S1054-139X(02)00445-7

Ghuman, S., Meyer-Weitz, A., \& Knight, S. (2012). Prevalence patterns and predictors of alcohol use and abuse among secondary school students in southern KwaZulu-Natal, South Africa: demographic factors and the influence of parents and peers. South African Family Practice Journal, 54(2), 132-138. https://doi.org/10.1080/20786204.2012.10874192

Gilman, L. M., \& Weber, J. S. (2007). How to use a statistical package. Retrieved on 20 September 2017 http://www.sagepub.com/prccj4e/study/resources/AppendixD.pdf

Greydanus, D. E., \& Patel, D. R. (2005). The adolescent and substance abuse: current concepts. Current Problems Pediatric and Adolescent Health Care, 35(3), 78-98. https://doi.org/10.1016/j.cppeds.2004.12.007

Gunasekara, F. I. (2012). Alcohol -the Body \& Health Effects: A brief overview. The Alcohol Advisory Council of 
New Zealand.

Leteka, J. M. M. (2007). Alcohol use/abuse amongst youths in selected high schools in Maseru city: The development of a health education programme (Lesotho). Dissertation Abstracts International Section A: Humanities and Social Sciences. Ann Arbor (MI): ProQuest Information \& Learning.

Madu, S. N., \& Matla, M. P. Q. (2003). Illicit Drug Use, Cigarette Smoking and Alcohol Drinking Behavior Among a Sample of High School Adolescents in the Pietersburg Area of the Northern Province, South Africa. Journal of Adolescence, 26(1), 121-136. https://doi.org/10.1016/S0140-1971(02)00120-3

Morojele, N., Parry, C., Brook, J., \& Kekwaletswe, C. (2012). Alcohol and drug abuse. Medical Research Council.

Newman, I. M., Shell, D. F., Ming, Q., Jianping, X., \& Maas, M. R. (2006). Adolecent Alcohol Use: mixed Research Approach. Journal of Guangxi University for Nationalities, 28(3),1-28.

Onya, H. E., \& Flisher, A. J. (2008). Prevalence of Substance Use Among Rural High School Students in Limpopo Province, South Africa. African Journal of Drug and Alcohol Studies, 7, 71-80.

Owo, O. I. (2013). Alcohol and other drugs: prevalence, demographic characteristics and perceived effects on the academic performance of high school students within the Mogalakwena Municipality of Limpopo Province. Thesis (M.Fam.Med.). University of the Witwatersrand.

Parry, C. D. H. (1998). Substance abuse in South Africa: country report focussing on young persons. Report Prepared for the WHO/UNDCP Regional Consultation - Global Initiative on Primary Prevention of Substance Abuse Among Young People, Harare, Zimbabwe, 24-26 February 1998. Medical Research Council.

Peltzer, K., \& Ramlagan S. (2007). Cannabis use trends in South Africa. South African Journal of Psychiatry, 13, 126-131. https://doi.org/10.4102/sajpsychiatry.v13i4.33

Peltzer, K., Davids, A., \& Njuho, P. (2011). Alcohol use and problem drinking in South Africa: findings from a national population-based survey. African Journal of Psychiatry, 14, 30-37. https://doi.org/10.4314/ajpsy.v14i1.65466

Ramsoomar, L., \& Morojele, N. K. (2012). Trends in alcohol prevalence, age of initiation and association with alcohol-related harm among South African youth: Implications for policy. South African Medical Journal, 102(7). https://doi.org/10.7196/SAMJ.5766

Schulte, M. T., Ramo, D., \& Brown, S. A. (2009). Gender differences in factors influencing alcohol use and drinking progression among adolescents. Clinical psychology review, 29(6), 535-547. https://doi.org/10.1016/j.cpr.2009.06.003

Seggie, J. (2012). Alcohol and South Africa's Youth. South African Medical Journal, 102(7). https://doi.org/10.7196/SAMJ.6003

Simbee, G. (2012). Prevalence of substance use and psychosocial influencing factors among secondary school students in Dodoma Municipality. MMed Dissertation. Muhimbili University of Health and Allied Sciences.

Smuts, S. L. (2009). Understanding the patterns of alcohol use among adolescents in a peri-urban historically disadvantaged community in the Western Cape Province, South Africa. Unpublished Masters in Public Health minithesis. University of the Western Cape.

Tshitangano, T. G., \& Tosin, O. H. (2016). Substance use amongst secondary school students in a rural setting in South Africa: Prevalence and possible contributing factors. African Journal of Primary Health Care \& Family Medicine. https://doi.org/10.4102/phcfm.v8i2.934

Van Walbeek, C., \& Blecher, E. (2015). The economics of alcohol use, misuse and policy in South Africa. South African World Health Organization Office.

Viljoen, D., Graig, P., Hymbaugh, K., Boyle, C., \& Blount, S. (2003). Foetal Alcohol Syndrome - South Africa. MMWR Weekly, 52, 660-662.

WHO. (2015). Alcohol factsheet. Date of access:12 October 2018. http://www.who.int/mediacentre/factsheets/

World Health Organization. (2017). Global Status Report on Alcohol and Health. Retrieved from http://www.who.int/substance_abuse/publications/global_alcohol_report/profiles/zaf.pdf

World Health Organization/United Nations International Drug Control Programme. UNDCP. (2003). Substance Use in Southern Africa Knowledge, Attitudes, Practices and Opportunities for Intervention. Summary of 
baseline assessments in the Republic of South Africa, the United Republic of Tanzania and the Republic of Zambia. Retrieved from http://www.who.int/substance_abuse/activities

\section{Copyrights}

Copyright for this article is retained by the author(s), with first publication rights granted to the journal.

This is an open-access article distributed under the terms and conditions of the Creative Commons Attribution license (http://creativecommons.org/licenses/by/4.0/). 